\section{(1) \\ CrossMark}

\title{
Effectiveness versus efficacy trials in COPD: how study design influences outcomes and applicability
}

\author{
Ashley Woodcock ${ }^{1}$, Isabelle Boucot ${ }^{2}$, David A. Leather ${ }^{2}$, Jodie Crawford ${ }^{3}$, \\ Susan Collier ${ }^{3}$, Nawar Diar Bakerly ${ }^{4,5}$, Emma Hilton $^{2}$ and Jørgen Vestbo ${ }^{1}$
}

Affiliations: ${ }^{1}$ Division of Infection, Immunity and Respiratory Medicine, Manchester Academic Health Sciences Centre, The University of Manchester and Manchester University NHS Foundation Trust, Manchester, UK. ${ }^{2}$ Global Respiratory Franchise, GSK, Brentford, UK. ${ }^{3}$ Respiratory Research and Development, GSK, Uxbridge, UK. ${ }^{4}$ Salford Royal NHS Foundation Trust, Salford, UK. ${ }^{5}$ Division of Infection, Immunity and Respiratory Medicine, Manchester Academic Health Science Centre, University of Manchester, Manchester, UK.

Correspondence: Ashley Woodcock, 2nd Floor ERC Building, Wythenshawe Hospital, Southmoor Road, M23 9LT, Manchester, UK.

E-mail: ashley.woodcockamanchester.ac.uk

@ERSpublications

Efficacy trials are less representative than effectiveness trials and both are required when evaluating treatments http://ow.ly/plwd30he4a2

Cite this article as: Woodcock A, Boucot I, Leather DA, et al. Effectiveness versus efficacy trials in COPD: how study design influences outcomes and applicability. Eur Respir J 2018; 51: 1701531 [https://doi.org/ 10.1183/13993003.01531-2017].

ABSTRACT Guidelines for chronic obstructive pulmonary disease (COPD) management are based largely on results from double-blind randomised controlled trials (RCTs) of efficacy. These trials have high internal validity and test whether a drug is efficacious, but they are conducted in highly selected populations that may differ significantly from patients with COPD seen in routine practice.

We compared the baseline characteristics, healthcare use and outcomes between the Salford Lung Study (SLS), an open-label effectiveness RCT, with six recent large-scale efficacy RCTs. We also calculated the proportion of SLS patients who would have been eligible for inclusion in an efficacy RCT by applying the inclusion criteria used in efficacy trials of combination treatments.

SLS patients were older, included more females and more current smokers, had more comorbidities (including asthma), and had more often experienced exacerbations prior to inclusion. In the SLS, rates of moderate or severe exacerbations, incidence of overall serious adverse events (SAEs), and SAEs of pneumonia were more frequent. A maximum of $30 \%$ of patients enrolled in the SLS would have been eligible for a phase IIIa regulatory exacerbation study.

Patients in large COPD efficacy RCTs have limited representativeness compared with an effectiveness trial. This should be considered when interpreting efficacy RCT outcomes and their inclusion into guidelines.

Received: July 272017 | Accepted after revision: Dec 092017

This study is registered at ClinicalTrials.gov with identifier number NCT01551758.

Support statement: This study was sponsored and funded by GlaxoSmithKline (study number: HZC115151). Funding information for this article has been deposited with the Open Funder Registry.

Conflict of interest: Disclosures can be found alongside this article at erj.ersjournals.com

Copyright @ERS 2018 


\section{Introduction}

Chronic obstructive pulmonary disease (COPD) is a major public health concern worldwide most commonly managed in primary care, and is proving to be a major burden to patients and healthcare systems $[1,2]$. Clinical guidelines for COPD management are based largely on results from double-blind randomised controlled trials (RCTs) of efficacy, which are accorded the strongest category of evidence [1, 3]. Such "efficacy RCTs" are usually conducted for the regulatory approval of new therapies to answer the question of whether the new therapy actually works as intended $[4,5]$. They focus on maximising internal validity and are designed to determine the effect of a medicine in ideal conditions.

However, it is questionable whether conventional efficacy RCTs are relevant to routine clinical practice and thus sufficient as the only source for registration. These trials are conducted in highly selected and homogeneous patient populations to avoid confounding factors such as comorbidities or diagnostic uncertainty. Inclusion criteria include strict spirometric criteria and smoking history, and patients with significant comorbidities (e.g. cardiovascular disease, or a current diagnosis or history of asthma, allergic rhinitis or atopy) are usually excluded [6-8]. Patients in RCTs are usually recruited in research clinics, are often healthier than patients in the general population [9] and frequently participate in multiple trials. Evidence suggests that this group of "persistent participators" may differ significantly from patients with COPD seen in routine primary care, typically ranging from $<10 \%$ to $30 \%$ of COPD patients seen in routine care [10-14].

In addition, efficacy RCTs involve intensive monitoring of the patients with frequent visits and procedures. Inhaler technique is rigorously checked, adherence is actively monitored and encouraged, and treatments are provided directly to patients by the investigator $[15,16]$. This highly controlled environment of an efficacy RCT does not reflect everyday practice, where patients with COPD are reviewed less frequently, inhaler technique is rarely checked and adherence to inhaled medicines is lower [17]. Therefore, study findings may be poorly generalisable to patients with COPD managed in everyday clinical practice despite a high internal validity.

In view of the aforementioned considerations, healthcare decision makers and providers are calling for data from more representative patients treated in a setting of routine care [15]. This can be achieved by effectiveness trials that are more able to fully explore the true benefit/risk ratio and value of a medicine, allowing clinicians to make more informed management decisions with patients [15]. In brief, whereas efficacy studies are carefully carried out experimental trials that test if a drug can work, an effectiveness study is a more simplistic trial testing if the drug does work. As a consequence, clinical guidelines may also be enhanced by integrating effectiveness as well as efficacy data [18]. Although improving external validity, effectiveness trials come at a price; often patients may have a less stringent diagnosis, are less well characterised and have poorer quality spirometry.

The Salford Lung Study (SLS) in COPD was designed to be conducted in a setting of everyday clinical practice to meet the need for effectiveness data to complement existing evidence from standard efficacy RCTs $[19,20]$. It was the world's first large-scale prospective, randomised study to evaluate the clinical effectiveness and safety of initiating a pre-licensed COPD medicine (fluticasone furoate/vilanterol (FF/VI); once daily in a novel dry powder inhaler) compared with continuing usual care in everyday clinical practice [20].

The aims of this article are 1) to compare the generalisability of the SLS by describing the similarities and differences of the patient characteristics and study conduct between the SLS and large COPD exacerbations efficacy trials carried out in the last 10 years, 2) to demonstrate the impact of patient selection and study conduct on study outcomes, and 3) to determine the proportion of SLS COPD patients that would have been eligible for inclusion in FF/VI phase IIIa regulatory exacerbation studies [6].

\section{Methods}

\section{SLS COPD study design}

The SLS was a 12-month open-label effectiveness RCT conducted in UK primary care that evaluated the effectiveness and safety of initiating FF/VI 100/25 $\mu \mathrm{g}$ once daily compared with continuing COPD maintenance therapy (usual care) (figure 1) [21].

\section{Patients}

Broad inclusion and minimal exclusion criteria were employed. Patients aged $\geqslant 40$ years, who had been diagnosed with COPD by their primary care physicians, with a history of exacerbations in the last 3 years and taking a regular maintenance inhaled therapy (inhaled corticosteroid (ICS) and/or long-acting muscarinic antagonist (LAMA) and/or long-acting $\beta$-agonist (LABA)), were randomised 1:1 to initiate FF/VI or to continue their usual care $[20,21]$. 


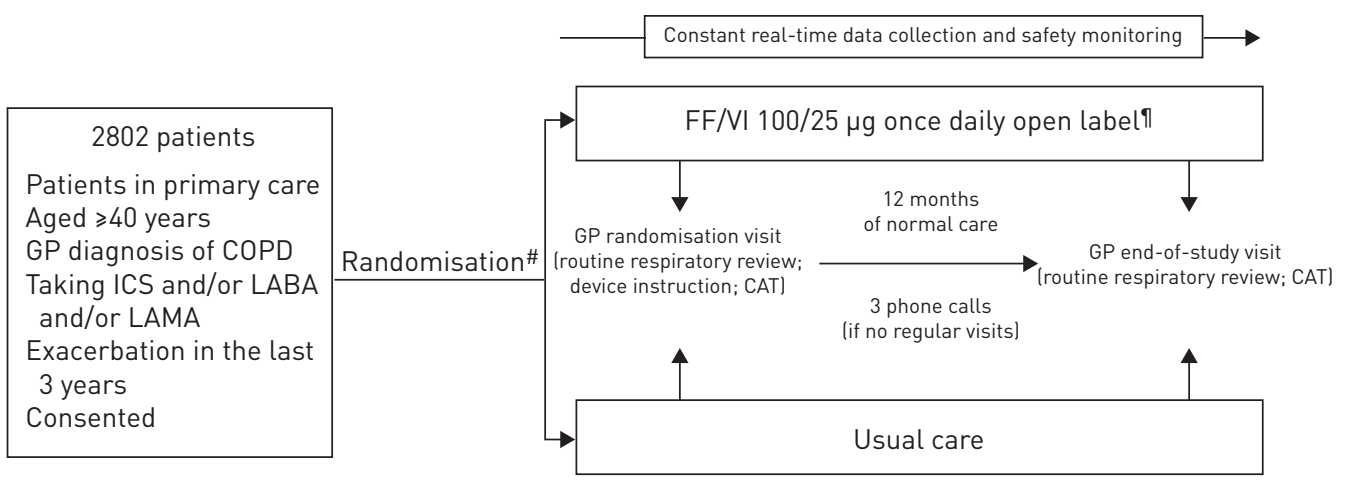

Physician free choice of COPD maintenance treatment

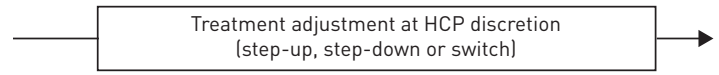

FIGURE 1 Salford Lung Study (SLS) study design. GP: general practitioner; COPD: chronic obstructive pulmonary disease; ICS: inhaled corticosteroid; LABA: long-acting $\beta$-agonist; LAMA: long-acting muscarinic antagonist; FF/VI: fluticasone furoate/vilanterol; CAT: COPD Assessment Test; HCP: healthcare professional. \#: randomisation stratified by recent exacerbation status and existing COPD maintenance therapy at baseline: ף: patient allowed to remain on LAMA in addition to their randomised treatment if already receiving LAMA therapy at randomisation. Information from [21].

\section{Recruitment and monitoring}

Patients were recruited on general practice. Patients were only seen face-to-face by the study team at baseline and at exit from the trial at 12 months. Study end-points and safety monitoring was carried out with an integrated primary and secondary care electronic health record (EHR). Patients collected their prescriptions from their usual pharmacy. General practitioners (GPs) were able to adjust medication throughout the study to allow for optimal treatment of COPD, as would be normal clinical practice. Patients were allowed to switch from FF/VI to usual care.

\section{End-points}

The primary end-point was the mean annual rate of moderate or severe exacerbations (symptoms that led to treatment with antibiotic agents or systemic glucocorticoids (or both), to hospital admission, or to scheduled or unscheduled hospital visits), with symptoms assessed by the COPD Assessment Test (CAT) and healthcare resource utilisation as secondary end-points. Safety outcomes included SAEs of pneumonia (defined as an adverse event of special interest, i.e. an adverse event that was considered to be possibly related to ICS and LABA), and other SAEs including fatal SAEs and adverse drug reactions (ADRs) [20, 21].

\section{Selection of large efficacy trials}

Based on a PubMed search using the search terms "COPD", "randomised clinical trial" and "exacerbations" (resulting in 994 publications), we selected a range of large double-blind efficacy RCTs using the following criteria: 1) efficacy RCTs recruiting COPD outpatients aged $\geqslant 40$ years, 2) enrolled at least 1000 patients with a diagnosis of COPD, 3) conducted in the last 10 years (2007-2016), 4) assessing inhaled ICS/LABA and/or LAMA/LABA at licensed dose, 5) COPD exacerbations as the primary end-point, and 6) duration of treatment of 1 year.

\section{Methods of analysis}

We compared baseline characteristics and healthcare use, and efficacy/effectiveness and safety outcomes, between the SLS and the selected large efficacy RCTs. Baseline characteristics included age, sex, smoking status, post-bronchodilator forced expiratory volume in $1 \mathrm{~s}$ (FEV1) \% pred, CAT score, exacerbation history and comorbidities. Where CAT score values from efficacy RCTs were not available, the values were derived from the St George's Respiratory Questionnaire score [22]. Outcomes included the rate of moderate or severe COPD exacerbations, the rate of hospitalised (severe) COPD exacerbations, overall SAEs, fatal events, SAEs of pneumonia and ADRs. In addition, rates of patient withdrawal were also compared.

In a separate post hoc analysis, we evaluated the proportion of patients who would have been eligible for the FF/VI phase IIIa regulatory studies with exacerbation as a primary outcome, using a stepwise approach [6]. The criteria we examined in sequence included baseline spirometry, available post-bronchodilator FEV1/forced vital capacity $(\mathrm{FVC})<0.70$, post-bronchodilator $\mathrm{FEV}_{1} \leqslant 70 \%$, smoking status and number of pack-years, history of current asthma, and history of at least one moderate or severe exacerbation in the prior 12 months. 


\section{Results}

\section{Selection of efficacy RCTs}

We assessed six large efficacy RCTs conducted in patients with COPD [6-8, 23-25]. The trials were carried out between 2007 and 2016, included patients aged $\geqslant 40$ years with a smoking history of at least 10 pack-years, with a post-bronchodilator spirometric FEV1/FVC $<0.70$ combined with post-bronchodilator FEV $1 \leqslant 70 \%$. The exclusion criteria included long-term oxygen therapy, acute phase of pulmonary rehabilitation, patients with comorbid asthma or other pulmonary disease, or other significant conditions (e.g. carcinoma, heart disease or diabetes). Table 1 shows the key study design characteristics of the six selected large RCTs.

\section{Patients characteristics and healthcare use at baseline}

Key patient characteristics in the ITT populations of the SLS and efficacy RCTs are summarised in table 2. SLS patients were older (mean age 67 versus 63-65 years in efficacy RCTs), included more females (51\% versus $24-43 \%$ ), a high proportion of current smokers (46\% versus 36-48\%) and had a high rate of comorbidities (77\%), including patients with asthma (22\%). Not all patients in the SLS underwent spirometry (21\% had not) and $5 \%$ of patients had never smoked. SLS patients had more exacerbations prior to inclusion (mean 2.01 moderate or severe exacerbations in the prior 12 months) compared with those included in efficacy RCTs (mean 1.2-1.7).

\section{Study outcomes in the SLS versus large efficacy trials}

Key findings are summarised in figure $2 \mathrm{a}$ and $\mathrm{b}$, and are detailed in table 3. In the SLS, the rate of patient withdrawals from treatment was very low (7\%) compared with efficacy RCTs (11-30\%) (table 1). The mean annual rate of moderate or severe exacerbations was substantially higher in both arms in the SLS (1.74 in the FF/VI arm and 1.90 in the usual care arm) compared with the efficacy RCTs, where the rate ranged from 0.45 to 1.19 (table 3 and figure 2a). However, there was no difference in the rate of severe exacerbations when comparing the SLS and the large efficacy trials (table 3). The incidence of overall SAEs (including fatal SAEs) and pneumonia SAEs was higher in the SLS (both arms) at 27-29\% and 6-7\%, respectively, compared with efficacy RCTs (13-24\% and $1-3.2 \%$ in ICS-containing arms, respectively) (table 3 and figure $2 \mathrm{~b}$ ). The incidence of ADRs in the FF/VI arm from the SLS COPD was similar to the incidence observed in the FF/VI arm in the FF/VI phase III exacerbation studies (15\% versus 17\%), The incidence of ADRs in the usual care arm of the SLS was lower than that in the FF/VI arm in both the SLS and FF/VI phase IIIa regulatory studies [6]. The incidence of fatal SAEs was low, but varied across the FF/VI and usual care arms of the SLS and the arms of efficacy RCTs (3\% versus $2 \%$ and $1-3 \%$, respectively). The patterns of SAEs and ADRs in the SLS COPD were as expected for this medicine class.

\section{Proportion of SLS patients eligible for inclusion in FF/VI phase IIla regulatory exacerbation studies}

Almost half (5658 out of $11720(48 \%)$ ) of COPD patients registered at the GP practices in Salford and South Manchester area taking part in the SLS were eligible for the SLS, based on a retrospective analysis of a database study carried out for the feasibility of the SLS [27], and of those eligible patients around half entered the study.

Of the 2802 patients enrolled in the SLS, 841 (30\%) would have been eligible for the phase III FF/VI studies (figure 3a) [6]. Most patients were excluded by spirometry (49\%), especially because of missing spirometry data at baseline (figure $3 \mathrm{~b}$ ). Of all the COPD patients in Salford eligible for inclusion in the SLS, $\sim 15 \%$ (841 out of 5658 patients) would have been eligible for entry to an efficacy RCT.

\section{Discussion}

In the SLS COPD study carried out in routine clinical practice, patients had a high burden of disease, more symptoms, more frequent exacerbations, more comorbidities and more SAEs (including SAEs of pneumonia) compared with patients in large COPD efficacy RCTs conducted for registration purposes.

Efficacy RCTs exclude patients because of age, disease severity and presence of comorbidities [10, 11, 13, 14, 28]. Data from an analysis of seven primary care databases in Europe has previously been compared with six large COPD efficacy RCTs [28]. In that analysis, as with the SLS, patients with COPD followed in primary care tended to be older, more commonly female and to have moderate airflow obstruction, but unlike the SLS had lower exacerbation rates. This probably relates to the SLS selecting patients with at least one exacerbation in the previous 3 years $(81 \%$ had an exacerbation within the last year). These data combined with the SLS show definitively that COPD patients enrolled in efficacy RCTs are unrepresentative of those seen in primary care. 
TABLE 1 Key study design characteristics of the six selected randomised controlled trials in chronic obstructive pulmonary disease (COPD)

\begin{tabular}{|c|c|c|c|c|c|c|c|c|}
\hline $\begin{array}{l}\text { First author } \\
\quad \text { [ref.] } \\
\text { (study } \\
\text { period) }\end{array}$ & $\begin{array}{c}\text { Patients } \\
\text { randomised } \\
\mathrm{n}\end{array}$ & Treatment arms & Duration & Key inclusion criteria & Key exclusion criteria & Primary end-point & $\begin{array}{c}\text { Study visits } \\
\text { after } \\
\text { randomisation } \\
\mathbf{n}\end{array}$ & $\begin{array}{c}\text { Withdrawal } \\
\text { rate } \%\end{array}$ \\
\hline $\begin{array}{l}\text { SHARAFKHANEH } \\
{[23]} \\
(2007- \\
2009)\end{array}$ & 1219 & $\begin{array}{c}\text { BUD/FM } \\
320 / 9 \mu \mathrm{g} \mathrm{pMDI} \\
\text { BUD/FM } \\
\text { 160/9 } \mu \mathrm{g} \mathrm{pMDI} ; \\
\text { FM } 12 \mu \mathrm{g} \mathrm{DPI}\end{array}$ & 1 year & $\begin{array}{c}\text { Age } \geqslant 40 \text { years; smoking history } \\
\geqslant 10 \text { pack-years; symptomatic } \\
\text { COPD }>2 \text { years (mMRC } \geqslant 2 \text { and } \\
\mathrm{BCSS} \geqslant 2 \text { ); pre- } \mathrm{BD} \text { FEV } 1 \leqslant 50 \% ; \\
\text { pre-BD FEV } 1 / \mathrm{FVC}<0.70 ; \text { history } \\
\geqslant 1 \text { moderate exacerbation in } \\
\text { prior } 12 \text { months }\end{array}$ & $\begin{array}{l}\text { Asthma history, allergy rhinitis; } \\
\text { subjects taking oral corticosteroid, } \\
\text { non-cardio-selective } \beta \text {-blockers, } \\
\text { leukotriene antagonists; pulmonary } \\
\text { rehabilitation <60 days; significant/ } \\
\text { unstable cardiovascular disorder; } \\
\text { clinically significant respiratory } \\
\text { tract disorder other than COPD and } \\
\alpha_{1} \text {-AT deficiency; any significant } \\
\text { comorbidities that may jeopardise } \\
\text { subject safety }\end{array}$ & $\begin{array}{l}\text { Exacerbation (requiring } \\
\text { oral or systemic } \\
\text { corticosteroid and/or } \\
\text { hospitalisation) (post hoc } \\
\text { analysis: oral or } \\
\text { systemic corticosteroid } \\
\text { and/or antibiotics and/or } \\
\text { hospitalisation) }\end{array}$ & 6 & 30 \\
\hline $\begin{array}{l}\text { WEDZICHA [24] } \\
(2009- \\
2011)\end{array}$ & 1199 & $\begin{array}{c}\text { BDP/FM } 100 / 6 \mu \mathrm{g} \\
\text { pMDI; FM } 12 \mu \mathrm{g} \\
\text { pMDI }\end{array}$ & 48 weeks & $\begin{array}{c}\text { Age } \geqslant 40 \text { years; smoking history } \\
\geqslant 10 \text { pack-years; mMRC } \geqslant 2 ; \\
\text { post-BD FEV } 1 \geqslant 30 \% \text { to }<50 \% ; \\
\text { post-BD FEV } 1 / F V C<0.7 ; \text { history } \\
\geqslant 1 \text { exacerbation in prior } \\
\quad 12 \text { months }\end{array}$ & $\begin{array}{l}\text { Current or past diagnosis of } \\
\text { asthma, allergy or other atopic } \\
\text { disease; clinically significant or } \\
\text { unstable concurrent diseases, } \\
\text { including clinically significant } \\
\text { laboratory abnormalities; evidence } \\
\text { of heart failure }\end{array}$ & $\begin{array}{c}\text { Pre-dose arm FEV } 1 \text { at } \\
12 \text { weeks; exacerbations } \\
\text { at } 48 \text { weeks }\end{array}$ & 5 & 15 \\
\hline $\begin{array}{l}\text { Dransfield [6] } \\
\text { (2009- } \\
2011)\end{array}$ & 3255 & $\begin{array}{c}\mathrm{FF} / \mathrm{VI} 50 / 25 \mu \mathrm{g} \\
\mathrm{DPI} ; \mathrm{FF} / \mathrm{VI} \\
100 / 25 \mu \mathrm{g} \mathrm{DPI} \\
\mathrm{FF} / \mathrm{VI} 200 / 25 \mu \mathrm{g} \\
\mathrm{DPI} \text {; VI } 25 \mu \mathrm{g} \mathrm{DPI}\end{array}$ & 1 year & $\begin{array}{l}\text { Age } \geqslant 40 \text { years; smoking history } \\
\geqslant 10 \text { pack-years; post-BD FEV } 1 \\
\leqslant 70 \% \text {; post-BD } \mathrm{FEV} 1 / \mathrm{FVC} \leqslant 0.7 ; \\
\text { history } \geqslant 1 \text { moderate/severe } \\
\text { exacerbation in prior } 12 \text { months }\end{array}$ & $\begin{array}{l}\text { Exacerbation in prior } 2 \text { weeks; } \\
\text { current asthma, atopy; other } \\
\text { respiratory disorders (lung cancer, } \\
\text { bronchiectasis, sarcoidosis, active } \\
\text { TB, etc.); } \alpha_{1} \text {-AT deficiency, lung } \\
\text { volume reduction surgery in prior } \\
\text { year; risk factors for pneumonia/ } \\
\text { chest radiograph with evidence of } \\
\text { pneumonia; LTOT } \geqslant 12 \mathrm{~h} \cdot \text { day }{ }^{-1} ; \\
\beta \text {-blocker treatment; clinically } \\
\text { significant uncontrolled diseases } \\
\text { (cardiovascular, neurological, renal, } \\
\text { etc.); alcohol or drug abuse }\end{array}$ & Exacerbations & 9 & 26 \\
\hline $\begin{array}{l}\text { WEDZICHA [7] } \\
\text { (2010- } \\
2012]\end{array}$ & 2224 & $\begin{array}{c}\text { IND/GLY } \\
110 / 50 \mu \mathrm{g} \mathrm{DPI} ; \\
\text { GLY } 50 \mu \mathrm{g} \mathrm{DPI} ; \\
\text { TIO } 18 \mu \mathrm{g} \mathrm{DPI}\end{array}$ & 64 weeks & $\begin{array}{c}\text { Age } \geqslant 40 \text { years; smoking history } \\
\geqslant 10 \text { pack-years; post-BD FEV } 1 \\
<50 \% \text {; post-BD } \mathrm{FEV} 1 / \mathrm{FVC}<0.7 \\
\quad \text { history } \geqslant 1 \text { moderate } \\
\text { exacerbation in prior } 12 \text { months }\end{array}$ & $\begin{array}{l}\text { Moderate/severe exacerbation in } \\
\text { prior } 6 \text { weeks or during run-in; RTI } \\
\text { in prior } 4 \text { weeks; daily LTOT; } \\
\text { concomitant pulmonary disease } \\
\text { (PAH, active TB, etc.); lung } \\
\text { lobectomy or lung volume } \\
\text { reduction; } \alpha_{1} \text {-AT deficiency; } \\
\text { clinically significant condition or } \\
\text { laboratory/ECG abnormalities (heart } \\
\text { disease, malignancy, narrow angle } \\
\text { glaucoma, long QT, etc.); diabetes; } \\
\text { history or current asthma, allergic } \\
\text { rhinitis, atopy or blood EOS count } \\
>600 \mathrm{~mm}^{-3}\end{array}$ & Exacerbations & 5 & 25 \\
\hline
\end{tabular}




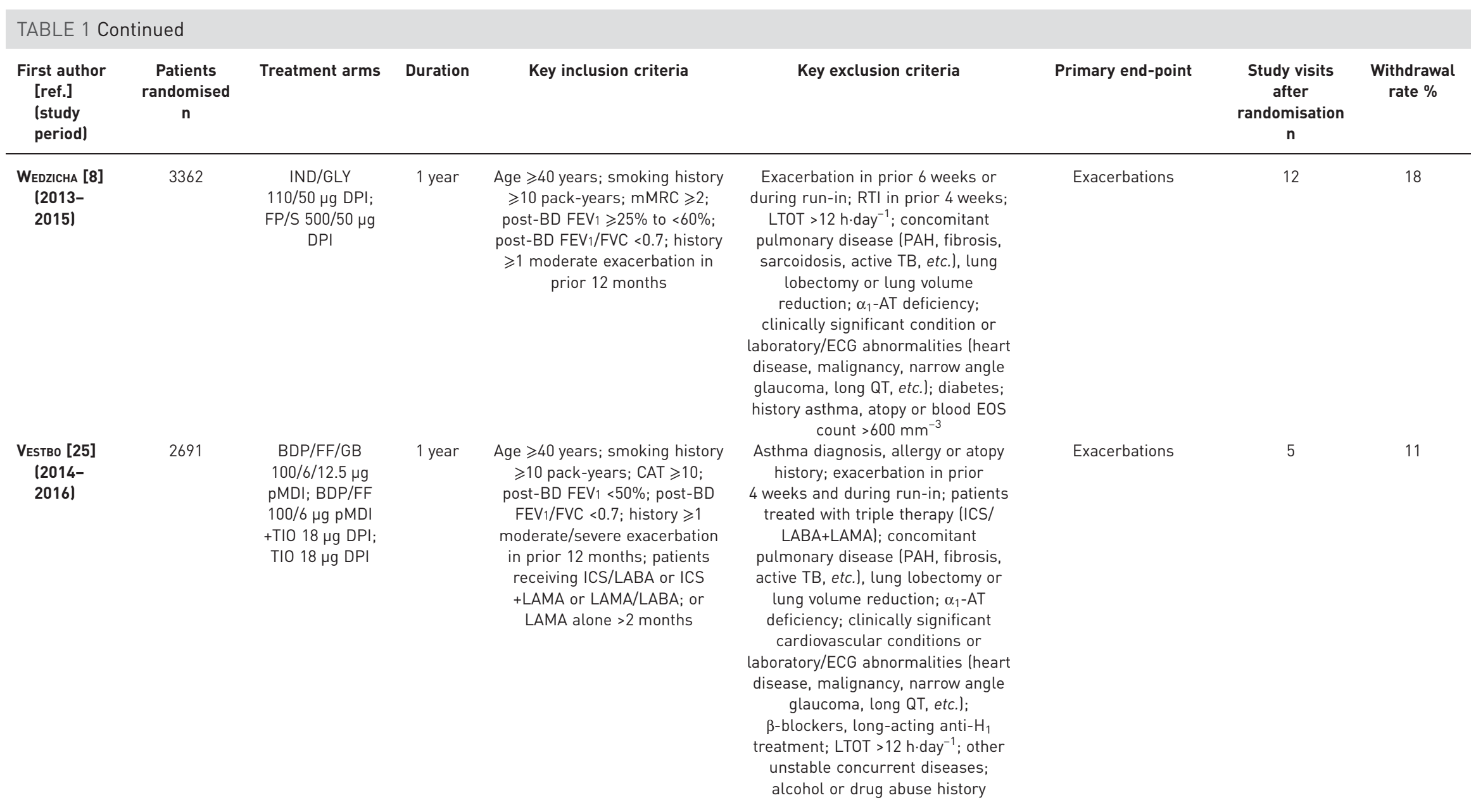

BUD/FM: budesonide/formoterol; pMDI: pressurised metered dose inhaler; FM: formoterol; DPI: dry powder inhaler; BDP/FM: beclometasone dipropionate/formoterol; FF/VI: fluticasone furoate/vilanterol; VI: vilanterol; IND/GLY: indacaterol/glycopyrronium; GLY: glycopyrronium; TIO: tiotropium; FP/S: fluticasone propionate/salmeterol; BDP/FF/GB: beclometasone dipropionate/formoterol fumarate/glycopyrronium bromide; BDP/FF: beclometasone dipropionate/formoterol fumarate; mMRC: modified Medical Research Council Dyspnoea scale; BCSS: breathlessness, cough and sputum score; BD: bronchodilator; FEV1: forced expiratory volume in 1 s; FVC: forced vital capacity; CAT: COPD Assessment Test; ICS: inhaled corticosteroid; LABA: long-acting $\beta$-agonist; LAMA: long-acting muscarinic antagonist; $\alpha_{1}$-AT: $\alpha_{1}$-antitrypsin; LTOT: long-term oxygen therapy; RTI: respiratory tract infection; PAH: pulmonary arterial hypertension; TB: tuberculosis; EOS; eosinophil. 
TABLE 2 Patient characteristics at baseline in intention-to-treat populations

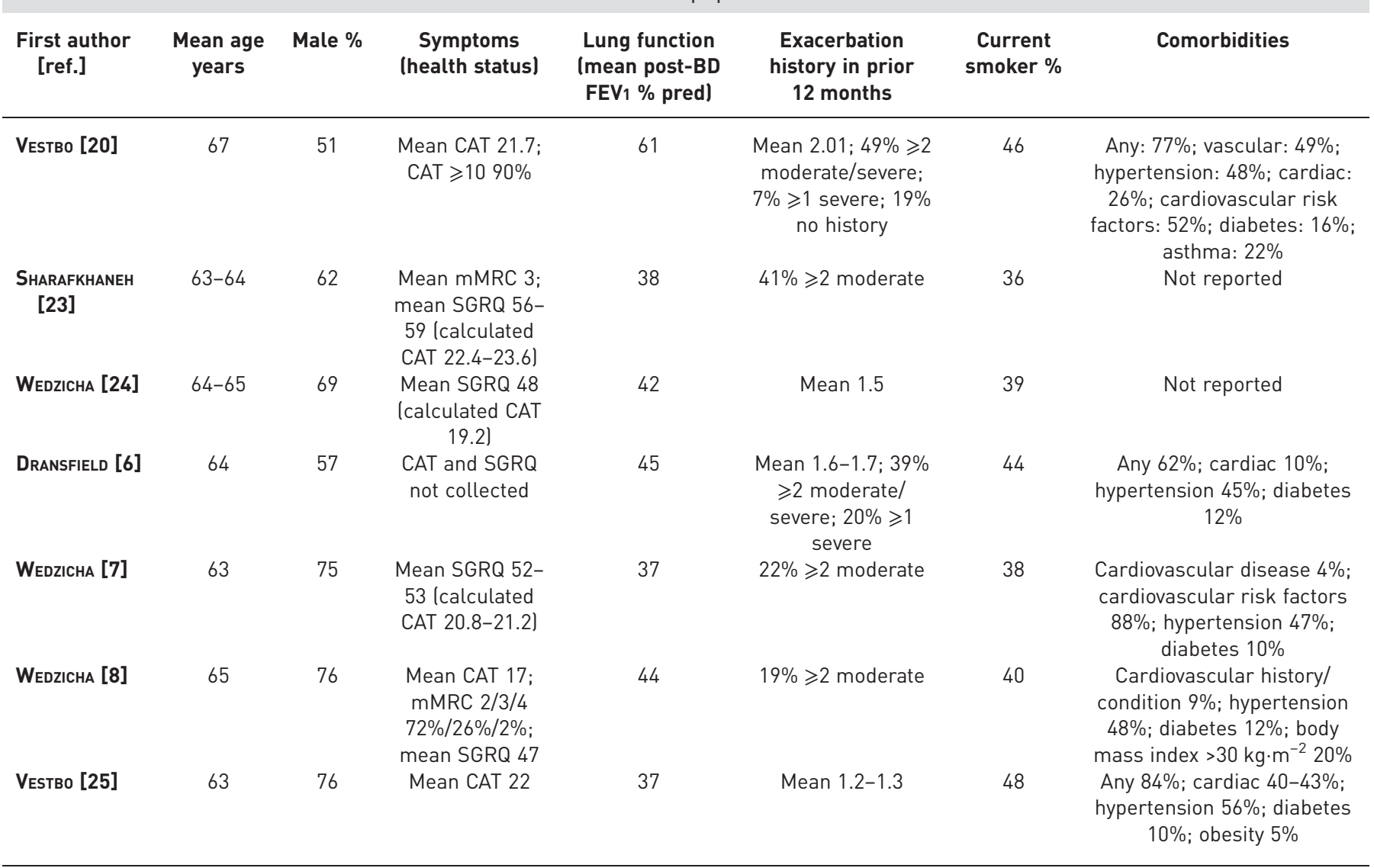

BD: bronchodilator; FEV1: forced expiratory volume in $1 \mathrm{~s}$; CAT: COPD Assessment Test; mMRC: modified Medical Research Council Dyspnoea scale; SGRQ: St George's Respiratory Questionnaire.

Efficacy RCTs also have other subtle enrolment criteria which make them less relevant to the population to whom the drug will be marketed. For example, patients may be excluded for lack of compliance during run-in or poor inhaler technique. This could eliminate any benefits in routine practice from an easier-to-use inhaler. In addition, the tight supervision in an RCT with repeated training on inhaler technique and encouragement to adherence just does not take place in routine care. In contrast, in the SLS, apart from the baseline and 12-month visits, there were no planned face-to-face study visits with the study team. The very low dropout rate in the SLS compared with efficacy RCTs probably reflects the "passive" nature of the SLS, with all routine care being carried out by the patient's GP, and that subjects could change from FF/VI back to usual care while remaining in the study. The dropout was up to 4 times higher in the efficacy trials compared with the SLS. With higher dropout rates, there is always a concern about the relevance of trial outcomes for those who did drop out. In addition, the data from the healthy survivor population remaining in an efficacy RCT may be even less relevant to everyday care. Effectiveness trials have other limitations. They often rely on assessments made as part of routine care, often lacking the rigour employed in an efficacy trial; for COPD this especially relates to the quality of spirometry. The study design also allows patients to change treatment, something that leads to exclusion from an efficacy trial. In the SLS, patients were allowed to switch from FF/VI to usual care (but not from usual care to FF/VI). Given the study findings, treatment switching is likely to dilute the study result as all analyses were done on an intention-to-treat basis, but more studies are needed on this aspect of effectiveness trials. An SLS supportive analysis was conducted, but not yet published, to assess the impact of switching on effectiveness outcomes and no impact was found. Finally, effectiveness trials are often carried out in a specific geographical location, as was the SLS. The impact of this on study outcomes has not been examined as, unfortunately, very few effectiveness trials in COPD exist. We are of course also limited in having only one effectiveness trial to compare with the larger number of published efficacy trials and subsequent effectiveness trials could differ from the SLS. 

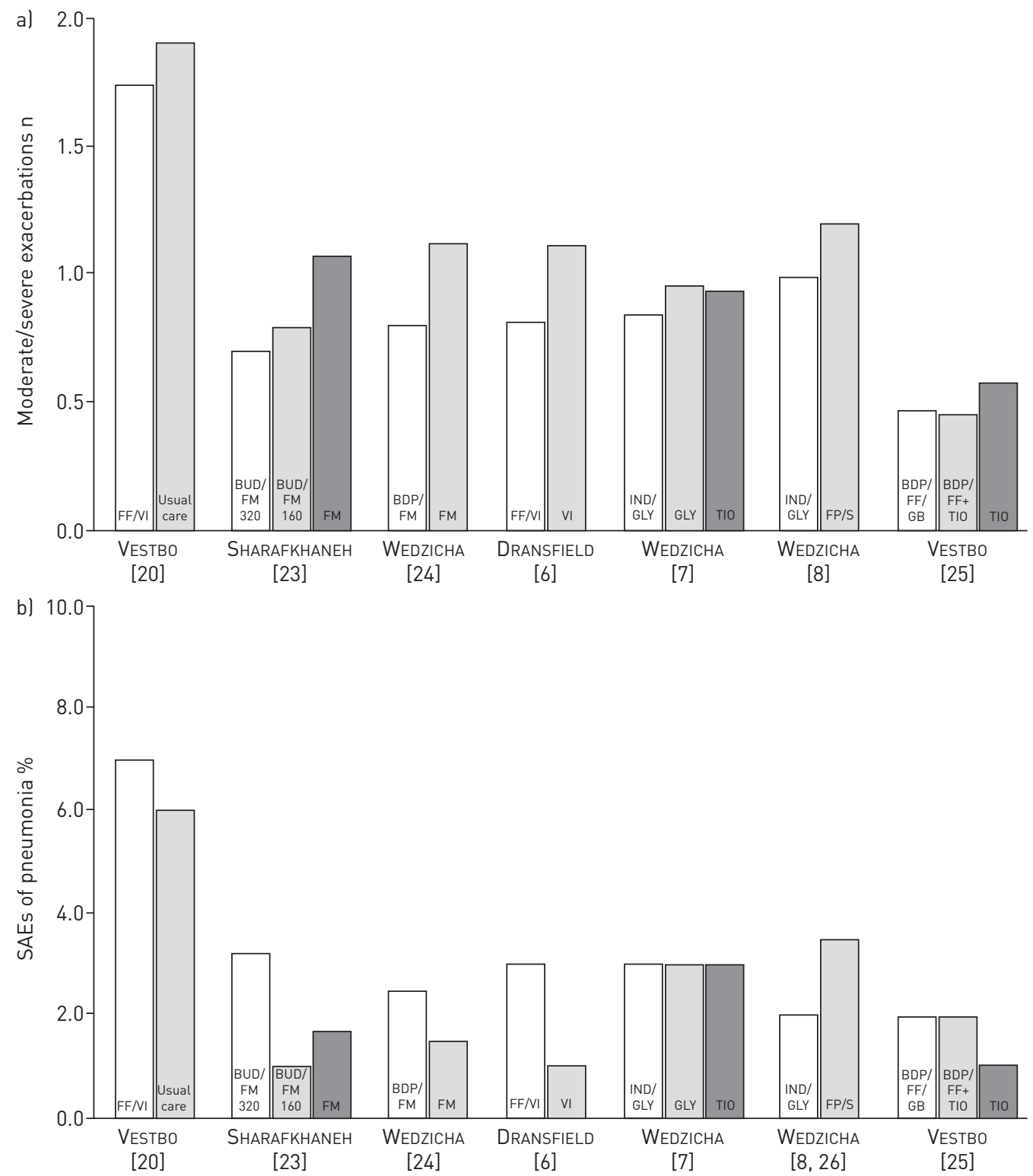

FIGURE 2 Comparison of the Salford Lung Study with other chronic obstructive pulmonary disease efficacy randomised controlled trials on effectiveness and safety outcomes: al moderate or severe exacerbations and b) serious adverse events (SAEs) of pneumonia. FF/VI: fluticasone furoate/vilanterol; BUD/FM: budesonide/ formoterol; FM: formoterol; BDP/FM: beclometasone dipropionate/formoterol; VI: vilanterol; IND/GLY: indacaterol/glycopyrronium; GLY: glycopyrronium; TIO: tiotropium; FP/S: fluticasone propionate/salmeterol; BDP/FF/GB: beclometasone dipropionate/formoterol fumarate/glycopyrronium bromide; BDP/FF: beclometasone dipropionate/formoterol fumarate.

The diagnosis of COPD was based on GP standard clinical practice, which did not always incorporate spirometric confirmation; indeed, $21 \%$ of patients in the SLS did not have spirometry. COPD efficacy RCTs usually exclude never-smokers, yet in the SLS, 5\% of subjects reported that they had never smoked. In the SLS, the $22 \%$ of patients with a concurrent diagnosis of asthma would have been excluded in a registration RCT, even though in routine practice many patients will commonly be labelled as both asthma and COPD $[1,29]$.

Only a small proportion of SLS patients (30\%) would have been eligible for the FF/VI phase IIIa exacerbation studies due to the typical multiple inclusion and exclusion criteria, which is consistent with the findings reported in the literature $[10,11,13,14,28]$. This proportion is likely an overestimate, since many patients could have been excluded on the basis of poor inhaler technique or poor adherence.

There is a lack of data comparing safety outcomes from efficacy versus effectiveness RCTs. In the SLS, there were more exacerbations, and a higher incidence of SAEs and fatal SAEs, likely due to enrolment of 
TABLE 3 Comparison of the Salford Lung Study with other chronic obstructive pulmonary disease efficacy randomised controlled trials on effectiveness and safety outcomes

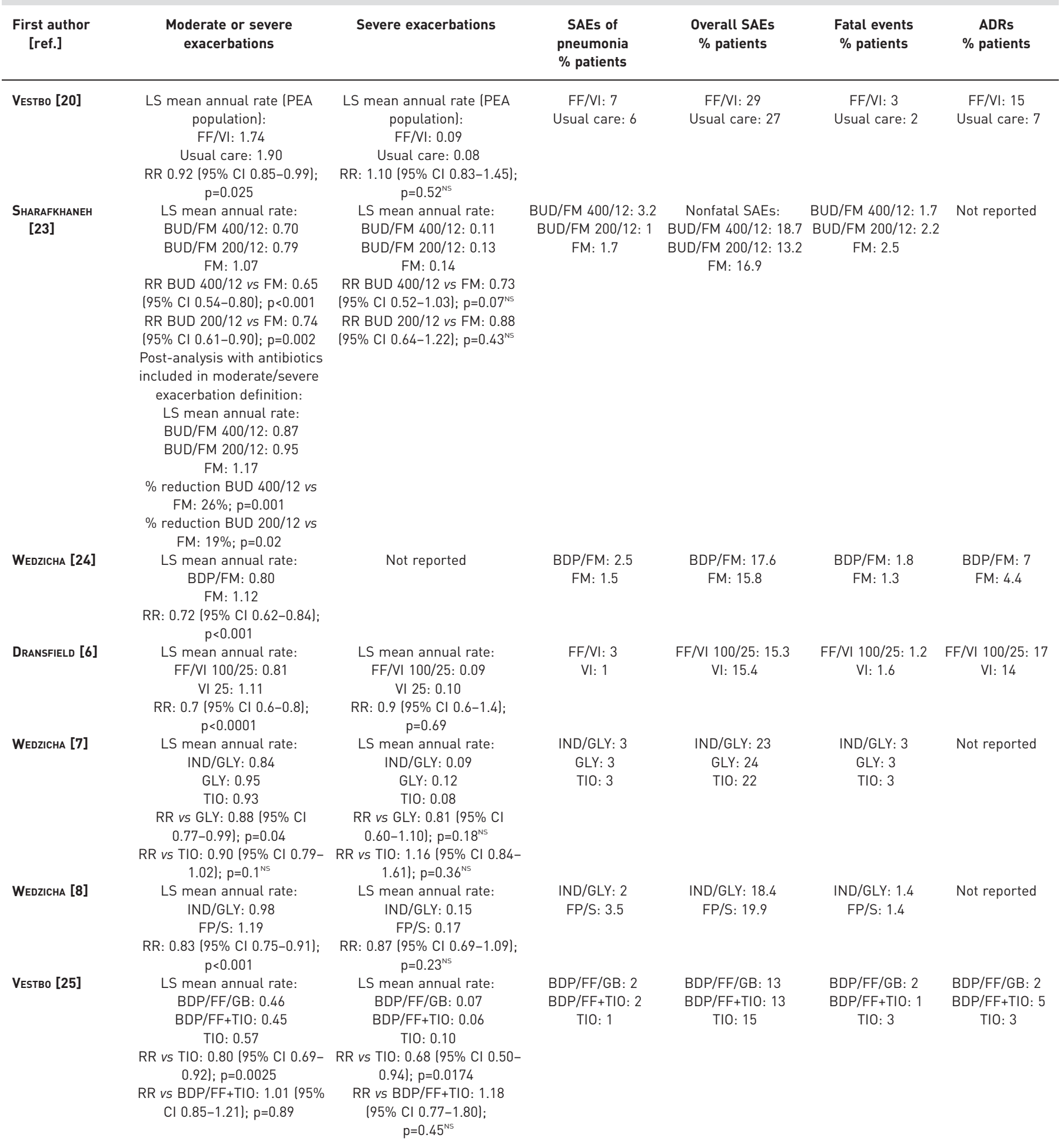

SAE: serious adverse event; ADR: adverse drug reaction; LS: least squares; PEA: primary effectiveness population; FF/VI: fluticasone furoate/ vilanterol; RR: rate ratio; NS: not significant; BUD/FM: budesonide/formoterol; FM: formoterol; BDP/FM: beclometasone dipropionate/ formoterol; VI: vilanterol; IND/GLY: indacaterol/glycopyrronium; GLY: glycopyrronium; TIO: tiotropium; FP/S: fluticasone propionate/salmeterol; BDP/FF/GB: beclometasone dipropionate/formoterol fumarate/glycopyrronium bromide; BDP/FF: beclometasone dipropionate/formoterol fumarate. 

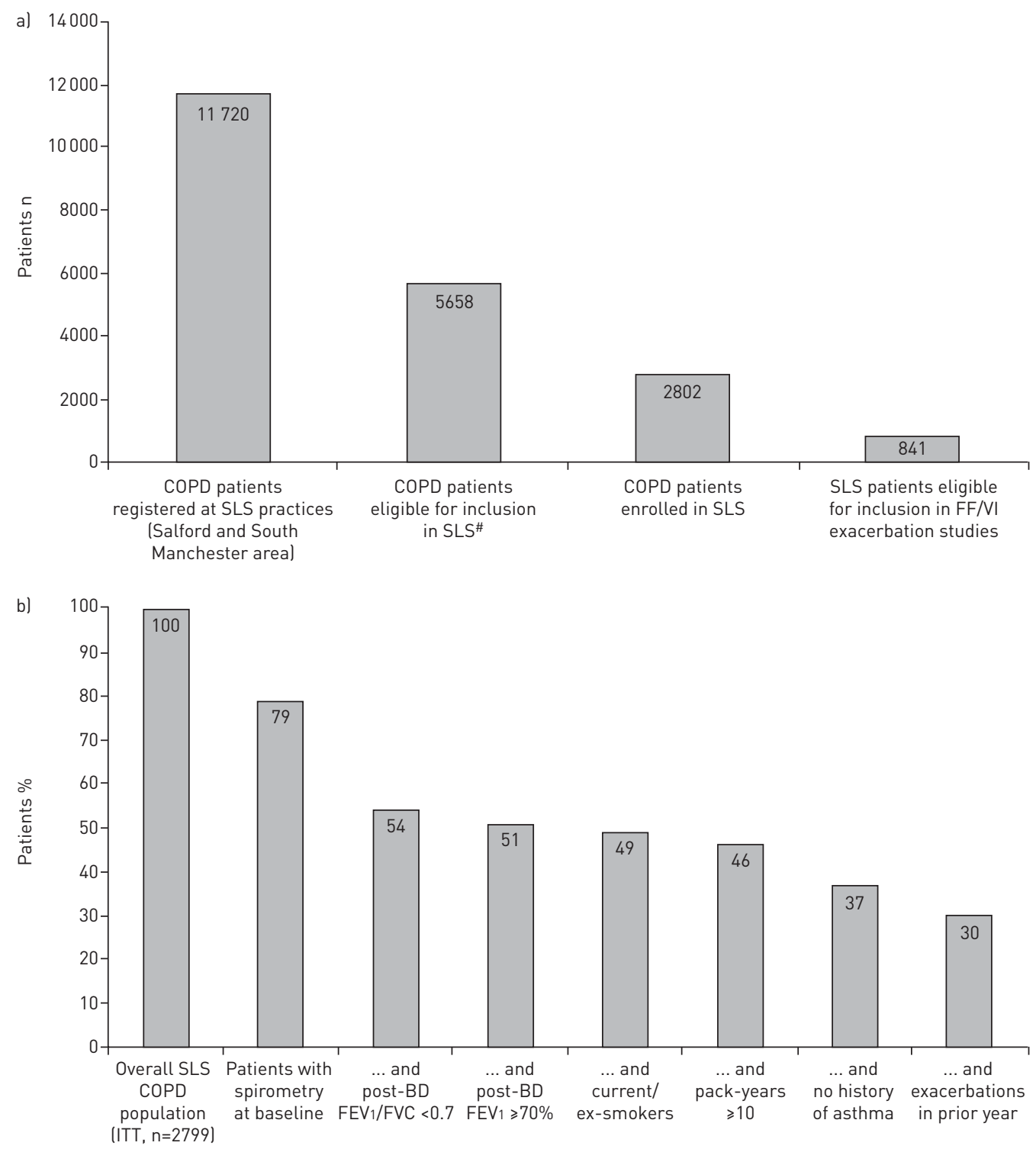

FIGURE 3 Generalisability of Salford Lung Study (SLS) patients: a) eligibility of SLS patients for inclusion in fluticasone furoate/vilanterol (FF/VI) phase IIla exacerbations studies and b) eligible SLS patients remaining after stepwise introduction of selected inclusion criteria from FF/VI phase Illa exacerbations studies [6]. COPD: chronic obstructive pulmonary disease; ITT: intention to treat; BD: bronchodilator; FEV1: forced expiratory volume in $1 \mathrm{~s}$; FVC: forced vital capacity. " : estimates based on retrospective analysis of the NorthWest EHealth linked database [27].

COPD patients with severe comorbidities. The higher rates of ADRs (where causality is attributed to the investigational medicine) may be due to a number of factors, including the open-label nature of the study, the unlicensed and unfamiliar FF/VI in a novel inhaler, and the "passive" continuous EHR monitoring for SAEs compared with the periodic active patient SAE reporting at infrequent face-to-face follow-up. In the SLS, all SAEs were captured by the EHR and reviewed weekly by the safety team with alerts to doctors.

In conclusion, we have confirmed the clear limitations of large efficacy RCTs in relation to their transferability to usual care. The patient population is more limited and the research environment is substantially different. Efficacy RCTs are essential to show that novel treatments have efficacy and are safe during research and development programmes. However, they should not be transferred straight into routine care guidelines without careful consideration. The SLS is a clinical effectiveness study designed to maintain scientific rigour through a prospective design, randomisation and stratification. We have enhanced the external validity and transferability into routine practice by recruiting a broad range of COPD patients and using remote monitoring with an EHR, albeit at the cost of less stringent diagnostics 
and poorer spirometric assessments. To fully evaluate any new treatments, we will need to provide additional effectiveness data in large unselected populations in routine clinical practice.

\section{Acknowledgements}

The authors wish to acknowledge the support of Andy Nicholls and Jamie Rees for the review and quality check of the data presented in this manuscript, both of whom are employees of GlaxoSmithKline (London, UK).

Author contributions: A. Woodcock, J. Vestbo, D.A. Leather, J. Crawford, S. Collier and N.D. Bakerly contributed to the study design and drafting the study protocol. I. Boucot, J. Crawford, D.A. Leather and E. Hilton were involved in the data analysis and interpretation.

\section{References}

1 Vogelmeier CF, Criner GJ, Martinez FJ, et al. Global Strategy for the Diagnosis, Management, and Prevention of Chronic Obstructive Lung Disease 2017 Report: GOLD Executive Summary. Eur Respir J 2017; 50: 1700671.

2 Foo J, Landis SH, Maskell J, et al. Continuing to confront COPD international patient survey: economic impact of COPD in 12 countries. PLoS One 2016; 11: e0152618.

3 National Institute for Health and Care Excellence. Chronic Obstructive Pulmonary Disease in Over 16s: Diagnosis and Management. NICE Clinical Guideline 101. 2010. www.nice.org.uk/guidance/cg101 Date last accessed: January 21, 2018.

4 European Medicines Agency. Guideline on Clinical Investigation of Medicinal Products in the Treatment of Chronic Obstructive Pulmonary Disease. 2012. www.ema.europa.eu/docs/en_GB/document_library/Scientific_ guideline/2012/2008/WC500130880.pdf Date last accessed: January 21, 2018.

$5 \quad$ Food and Drug Administration. Chronic Obstructive Pulmonary Disease: Developing Drugs for Treatment. Guidance for Industry. 2016. www.fda.gov/downloads/drugs//guidances/ucm071575.pdf Date last accessed: January 21, 2018.

6 Dransfield MT, Bourbeau J, Jones PW, et al. Once-daily inhaled fluticasone furoate and vilanterol versus vilanterol only for prevention of exacerbations of COPD: two replicate double-blind, parallel-group, randomised controlled trials. Lancet Respir Med 2013; 1: 210-223.

7 Wedzicha JA, Decramer M, Ficker JH, et al. Analysis of chronic obstructive pulmonary disease exacerbations with the dual bronchodilator QVA149 compared with glycopyrronium and tiotropium (SPARK): a randomised, double-blind, parallel group study. Lancet Respir Med 2013; 1: 199-209.

8 Wedzicha JA, Banerji D, Chapman KR, et al. Indacaterol-glycopyrronium versus salmeterol-fluticasone for COPD. N Engl J Med 2016; 374: 2222-2234.

$9 \quad$ Ford I, Norrie J. Pragmatic trials. N Engl J Med 2016; 375: 454-463.

10 Herland $\mathrm{K}$, Akselsen JP, Skjonsberg $\mathrm{OH}$, et al. How representative are clinical study patients with asthma or COPD for a larger "real life" population of patients with obstructive lung disease? Respir Med 2005; 99: 11-19.

11 Travers J, Marsh S, Caldwell B, et al. External validity of randomised controlled trials in COPD. Respir Med 2007; 101: 1313-1320.

12 Walker S, Fingleton J, Weatherall M, et al. Limited generalisability of UPLIFT findings to clinical practice. Thorax 2013; 68: 1066-1067.

13 Scichilone N, Basile M, Battaglia S, et al. What proportion of chronic obstructive pulmonary disease outpatients is eligible for inclusion in randomised controlled trials. Respiration 2014; 87: 11-17.

14 Halpin DMG, Kerkhof M, Soriano JB, et al. Eligibility of real-life patients with COPD for inclusion in trials of inhaled long-acting bronchodilator therapy. Respir Res 2016; 17: 120-132.

15 Treweek S, Zwarenstein M. Making trials matter: pragmatic and explanatory trials and the problem of applicability. Trials 2009; 10: 37 .

16 Singal AG, Higgins PD, Waljee AK. A primer on effectiveness and efficacy trials. Clin Transl Gastroenterol 2014; 5: e45.

17 Penning-van Beest F, van Herk-Sukel M, Gale R, et al. Three-year dispensing patterns with long-acting inhaled drugs in COPD: a database analysis. Respir Med 2011; 105: 259-265.

18 Wong GWK, Miravitlles M, Chisholm A, et al. Respiratory guidelines - which real world? Ann Am Thorac Soc 2014; 11: Suppl. 2, S85-S91.

19 New JP, Bakerly ND, Leather D, et al. Obtaining real-world evidence: the Salford Lung Study. Thorax 2014; 69: $1152-1154$

20 Vestbo J, Leather D, Diar Bakerly N, et al. Effectiveness of fluticasone furoate-vilanterol for COPD in clinical practice. N Engl J Med 2016; 375: 1253-1260.

21 Bakerly N, Woodcock A, New J, et al. The Salford Lung Study protocol: a pragmatic, randomised phase III real-world effectiveness trial in chronic obstructive pulmonary disease. Respir Res 2015; 16: 101.

22 Jones PW, Tabberer M, Chen WH. Creating scenarios of the impact of COPD and their relationship to COPD Assessment Test (CATTM) scores. BMC Pulm Med 2011; 11: 42.

23 Sharafkhaneh A, Southard JG, Goldman M, et al. Effect of budesonide/formoterol pMDI on COPD exacerbations: a double-blind, randomized study. Respir Med 2012; 106: 257-268.

24 Wedzicha JA, Singh D, Vestbo J, et al. Extrafine beclomethasone/formoterol in severe COPD patients with history of exacerbations. Respir Med 2014; 108: 1153-1162.

25 Vestbo J, Papi A, Corradi M, et al. Single inhaler extrafine triple therapy versus long-acting muscarinic antagonist therapy for chronic obstructive pulmonary disease (TRINITY): a double-blind, parallel group, randomised controlled trial. Lancet 2017; 389: 1919-1929.

26 Wedzicha JA, Vogelmeier CF, Ayers T, et al. Respiratory safety profile of indacaterol/glycopyrronium versus salmeterol/fluticasone: results from the FLAME study. Eur Respir J 2017; 50: PA1075.

27 Elkhenini HF, Davis KJ, Stein ND, et al. Using an electronic medical record (EMR) to conduct clinical trials: Salford Lung Study feasibility. BMC Med Inform Decis Mak 2015; 15: 8-17.

28 Kruis AL, Ställberg B, Jones RCM, et al. Primary care COPD patients compared with large pharmaceutically-sponsored COPD studies: an UNLOCK validation study. PLoS One 2014; 9: e90145.

29 Wurst KE, Kelly-Reif K, Bushnell GA, et al. Understanding asthma-chronic obstructive pulmonary disease overlap syndrome. Respir Med 2016; 110: 1-11. 